\title{
A new-type flexible rock-shed under the impact of rock block: initial experimental insights
}

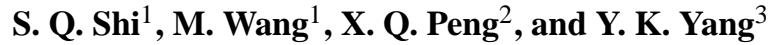 \\ ${ }^{1}$ Department of Civil Engineering, Logistical Engineering University, Chongqing 401311, China \\ ${ }^{2}$ School of Materials Science and Engineering, Shanghai Jiao Tong University, Shanghai 20030, China \\ ${ }^{3}$ Geobrugg (Chengdu) Co., Ltd., Chengdu 611731, China \\ Correspondence to: M. Wang (wangmin198217@163.com)
}

Received: 19 June 2013 - Published in Nat. Hazards Earth Syst. Sci. Discuss.: 9 August 2013

Revised: 24 October 2013 - Accepted: 23 November 2013 - Published: 18 December 2013

\begin{abstract}
A new concept of flexible rock-shed is proposed in this paper. The flexible rock-shed is made of flexible nets held up by a specially designed, steel vaulted structure. A $1: 1$ prototype is manufactured and tested for functional evaluation with an impact experiment. It is shown that the structure can stand for an impact energy of about $250 \mathrm{~kJ}$ without observable rupture of the flexible nets or cables and can be put into service again with some maintenances on the steel vaulted structure. Experimental data such as local strains, peak loads and impact times are recorded by dynamic strain gauges, load cells and a high-speed camera for structural analysis and some complementary suggestions of improving and designing are offered with respect to the joints and components. Finally, the advantages and limitations of the flexible rock-shed are outlined and the limits of the present experimental investigation and the future research for the flexible rock-shed are proposed.
\end{abstract}

\section{Introduction}

Rockfall can cause a lot of damage to highways, railways and infrastructure built along steep slopes and seriously restricts economy activities and transportation construction. In many cases, therefore, suitable protection measures are necessary. The protection measures against rockfall consist of active methods and passive methods (Bertolo et al., 2009). The active methods, such as rock-bolting, grouted bars, shotcreting, blasting and anchored cable nets, etc. are to prevent the detachment of blocks from their original position or to restrict the trajectory of the rockfall. However, in some cases, the protected regions are larger and the active methods are not easy to execute or are very costly and not effective (Sasiharan et al., 2006; Castro-Fresno et al., 2008; Blanco-Fernandez et al., 2011; Giacomini et al., 2012), thereby the passive methods are the alternative structural countermeasure approaches (Dhakal et al., 2011). The passive methods do not directly interfere in the process of rockfall, but control the dynamic effects of moving rockfall. Embankments, ditches, concrete walls, flexible barriers and rock-sheds can be classified into passive methods.

Among the passive methods, flexible barriers may be the most common protection measures against rockfall for the low- to medium-impact energy rockfall hazards (Vogel et al., 2009). Much research has already been performed on such barriers in recent years, including the full-scale physical modelling (Smith and Duffy, 1990; Peila et al., 1998; Gottardi and Govoni, 2010; Buzzi et al., 2013) and numerical modelling (Nicot et al., 2001; Cazzani et al., 2002; Volkwein et al., 2005; Dhakal et al., 2012; Gentilini et al., 2013). The design of the flexible barriers firstly involves the evaluation of possible paths of detachable rockfall, rockfall impact velocity and kinetic energy. Then the location is chosen for constructing the systems to prevent rockfall. The past studies on the rockfall analysis have been carried out for designing and accessing passive protection methods (Azzoni et al., 1995; Chau et al., 2002; Giani et al., 2004; Topal et al., 2007; Pantelidis et al., 2011; Lambert et al., 2013) and several computer programs have already been developed (Guzzetti et al., 2002; Crosta and Agliardi, 2004; Agliardi et al., 2009; Masuya et al., 2009). However, the trajectory of rockfall, such as bounding height or runout length, is difficult to predict due to the 


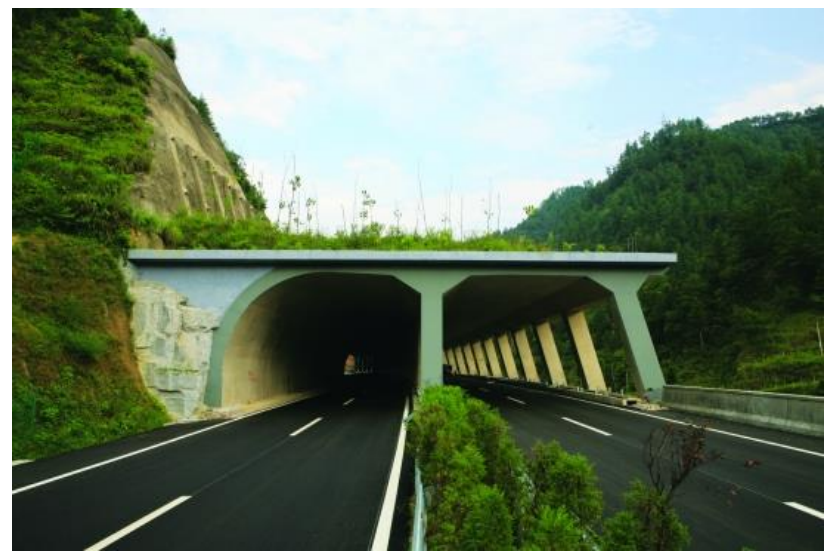

Fig. 1. Rock-shed on the Chongqing to Hunan highway with reinforced concrete columns, foundation and a roof slab; the width of the road for single pass is $8.5 \mathrm{~m}$ (Chongqing daily press photos).

inherent randomness or in some cases would overtop the barriers reaching the object to be the protection. This makes these flexible barriers far from sufficient. To solve this problem, rock-shed was invented to directly cover the roads and other spots (Fig. 1). This structure is composed of reinforced concrete columns, foundations and a roof slab and has good stiffness and protection performance, but needs a massive foundation due to the deadweight of the structure. In addition, constructing such foundations along steep slopes with frequently poor-quality bedrock is usually very difficult and expensive (Labiouse et al., 1996; Schellenberg, 2009).

Over the past decades, many research efforts have been devoted to overcoming the disadvantages of rock-sheds by converting rigid rock-sheds into semi-rigid ones and aiming to reduce the impact load of rockfall, the weight of the structure, construction costs and difficulty. The widely used forms at this stage are covering a soil layer on the roof slab (Kishi et al., 2002; Pichler et al., 2005; Kawahara and Muro, 2006; Schellenberg, 2009; Bhatti and Kishi, 2010), or developing a new rock-shed (structurally dissipating rock-shed, SDR) made of reinforced concrete slabs held up by specially designed supports that act as a type of expendable fuse to absorb rockfall energy (Mougin et al., 2005; Delhomme et al., 2005, 2007; Wendeler et al., 2013). With the aim of developing a structure which is simple to build and adaptive to the requirements of convenient and emergent construction, a new concept of flexible rock-shed is proposed in this paper, which can be manufactured at a factory and field-assembled. The flexible rock-shed (Fig. 2) is mainly composed of a steel vaulted structure and flexible nets. This structure mixes the flexible barriers and structural rock-sheds to provide a relatively lightweight, but spatially continuous protection structure. On the one hand, this structure fully takes advantage of the flexibility, high-strength and high-impact resistance of flexible nets. On the other hand, easy processing and molding characteristics of metal materials are utilized for the steel

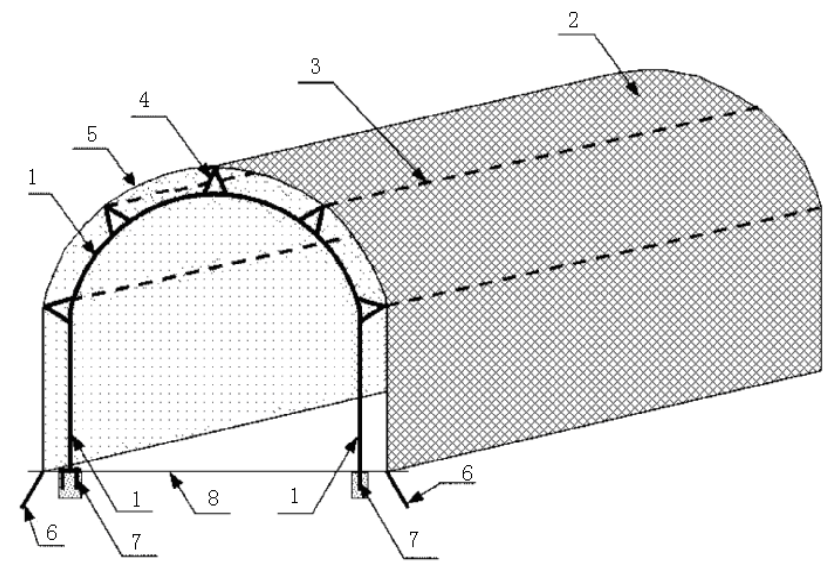

Fig. 2. Flexible rock shed composed of steel vaulted structure and flexible nets. 1: Steel vaulted structure; 2 : flexible nets; 3 : longitudinal support cable; 4: net-hanging bracket; 5: hoop support cable; 6: cable anchor; 7: anchor bolt; 8: ground.

vaulted structure to satisfy various structural forms with aesthetic advantages.

\section{Design strategy and protection capacity of flexible rock-shed}

The design strategy of the flexible rock-shed from concept to actual product is divided into three stages:

1. design the configuration dimensions of the system based on the requirements of the protected subject, such as the width of the pass road or the limited height of the vehicles;

2. according to the energy range of previously investigated rockfalls, select the appropriate flexible nets and then design the support systems, including the crosssectional sizes of the structural elements and the connection joints between the elements;

3. calculate the force transferred from the structure and design the foundations of the flexible rock-shed.

The flexible rock-shed relies much on the deformation of the flexible nets for energy absorption. In a general case, the flexible nets can absorb more energy through larger deformation, but in design, the adequate safety distance between the system and the ground to be protected must be taken into account. In addition, rockfall occurs in very different conditions and involves different block sizes, energy and velocity ranges and so on. However, in many regions of the world, such as in Australia and Japan, much lower values of impact energy have been involved, ranging from 25 to $250 \mathrm{~kJ}$ due to the nature of the geological environments (Muraishi et al., 2005; Buzzi et al., 2013). Therefore, compared to flexible barriers and concrete rock-sheds, the 


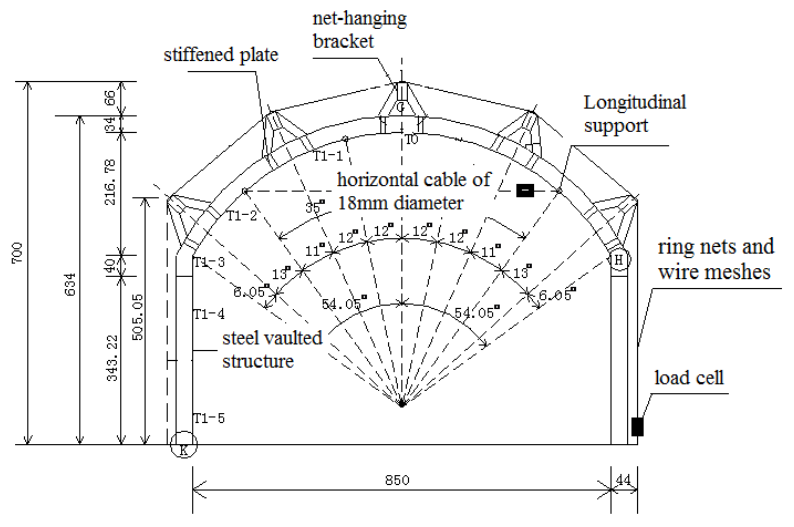

(a)

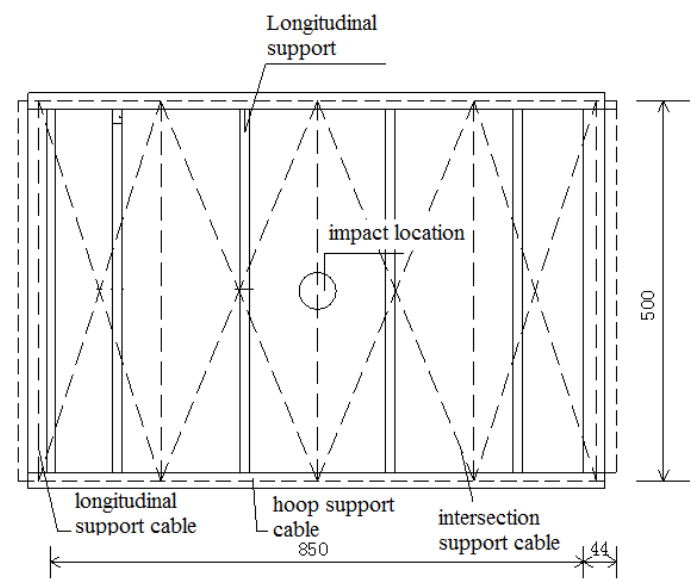

(b)
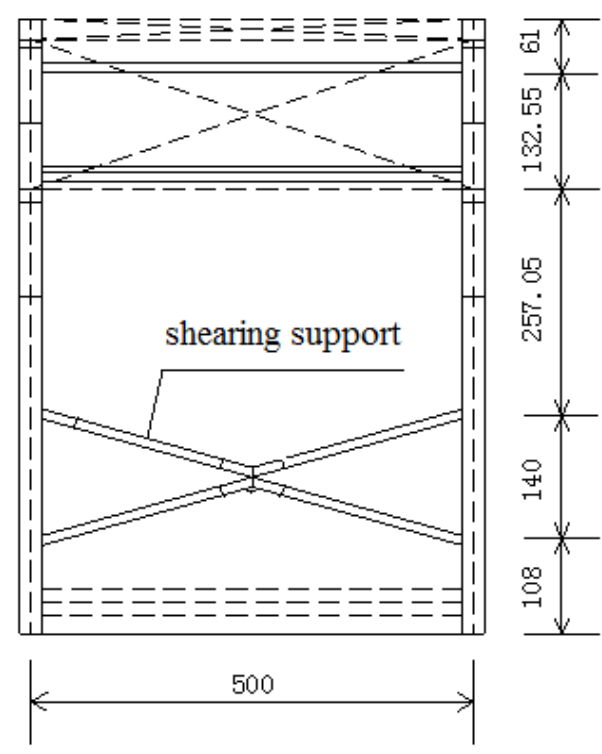

(c)

Fig. 3. The design of a single-span flexible rock-shed (unit:cm). (a) Front view of the designed flexible rock-shed. (b) Top view of the flexible rock-shed. (c) End view of the flexible rock-shed.

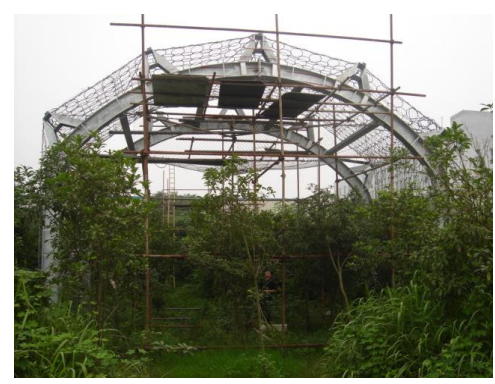

(a)

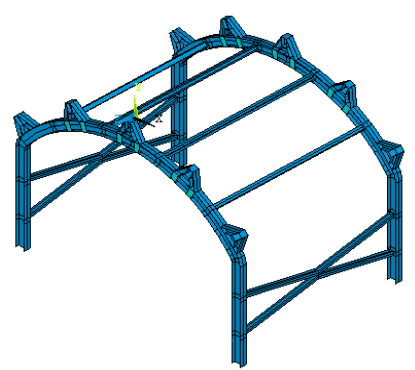

(b)

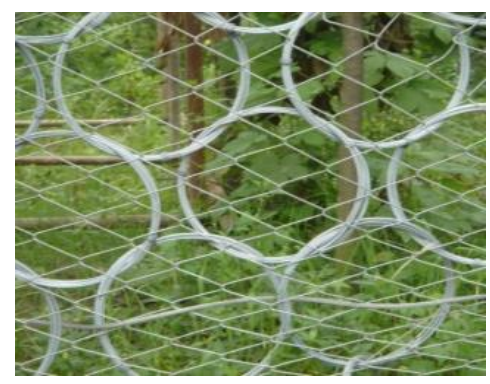

(c)

Fig. 4. (a) Flexible rock-shed constructed and tested on Chengdu, China; (b) steel vaulted structure; (c) ring nets with diameter $300 \mathrm{~mm}$ and TECCO wire meshes G65.

flexible rock-shed has focused on low levels of impact energy ranged from 25 to $250 \mathrm{~kJ}$, considering economic factors, safety distance, technical limitations and kinetic energy levels of rockfall that happened in normal conditions. The speed of rockfall ranges from a few meters per second to up to $25 \sim 30 \mathrm{~m} \mathrm{~s}^{-1}$ (Peila and Ronvo, 2009) and owing to the fact that damages were frequently caused by impacts of small blocks with high velocities, thus producing the nets' perforation, the maximum speed of rockfall impacting the system is constrained to $25 \mathrm{~m} \mathrm{~s}^{-1}$ (Cazzani et al., 2002; Volkwein et al., 2011; Spadari et al., 2012).

In accordance with the dimension requirements for twoway traffic, the designed flexible rock-shed is a structure $8.5 \mathrm{~m}$ in width, $5 \mathrm{~m}$ in span and $7.0 \mathrm{~m}$ in height (Fig. 3). There are longitudinal supports between two steel vaulted structures. A $1: 1$ prototype of flexible rock-shed (Fig. 4a) with a vaulted structure is designed and manufactured (Fig. 4b), in which flexible nets are chosen to be subjected to direct 
Table 1. The time lapse from the first contact of the block with the flexible rock-shed.

\begin{tabular}{lr}
\hline The key point frames of video camera & Time lapse (s) \\
\hline $\begin{array}{l}\text { Block contacting with rock-shed } \\
\text { Block down to the lowest point and }\end{array}$ & 0 \\
steel vaulted structure beginning to rebound & 0.143 \\
Block rebounding and steel vaulted & \\
structure stopping rebounding & 0.227 \\
Block rebounding off flexible rock-shed & \\
Block flying off one side of rock-shed & 0.533 \\
\hline
\end{tabular}

impact. The flexible nets are composed of ring nets and TECCO wire meshes G65 (Fig. 4c) and the flexible rockshed is designed to stand for an impact energy up to $250 \mathrm{~kJ}$.

\section{Experimental set-up}

Flexible barriers consist of flexible nets supported by steel cables with inelastic brake elements and columns and have been constructed worldwide, resulting in the development of different national testing procedures (Gerber, 2001; EOTA, 2008). The current flexible rock-shed is a combination of a flexible barrier and a rock-shed. Accordingly, the procedure for testing the flexible rock-shed is designed and implemented with reference to testing procedures of flexible barriers and concrete rock-sheds.

Pre-fabricated 14-face polyhedron reinforced-concrete block is used to simulate rockfall (Fig. 5a). In the experiment, the mass of the reinforced-concrete block is approximately $800 \mathrm{~kg}$, and the density is $\rho=2500 \mathrm{~kg} \mathrm{~m}^{-3}$. A steel cable hanger (Fig. 5a) with a volume of $V_{1}=769.23 \mathrm{~cm}^{3}$ is embedded beforehand to hoist the block by a crane. The edge length $b$ of the block can be calculated as

$b=\left[\left(\frac{m}{\rho}+V_{1}\right) \times \frac{81}{77}\right]^{\frac{1}{3}}$.

The test involves dropping the block from a given height in order to obtain a fixed energy of $250 \mathrm{~kJ}$ and an impact velocity of $25 \mathrm{~m} \mathrm{~s}^{-1}$. The height lifted by the crane and the impact velocity are calculated by the formula below:

$h=\frac{E}{m g}+h_{1}, \quad v=\sqrt{2 g\left(h-h_{1}\right)}$,

where $E$ is the kinetic energy of the block; $h_{1}$ is the height of the flexible rock-shed; $g$ is the acceleration of gravity.

The block is lifted to the dropping height of about $39 \mathrm{~m}$. To ensure that the block can be released freely, an unhooking apparatus is designed and installed between the hanger and the block (Fig. 5b). The unhooking apparatus can be remotely manipulated to implement free fall of the block. A plumb line is used to determine the impact position so that

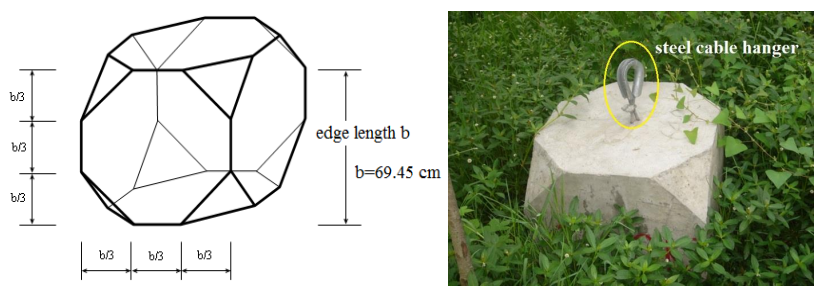

(a)

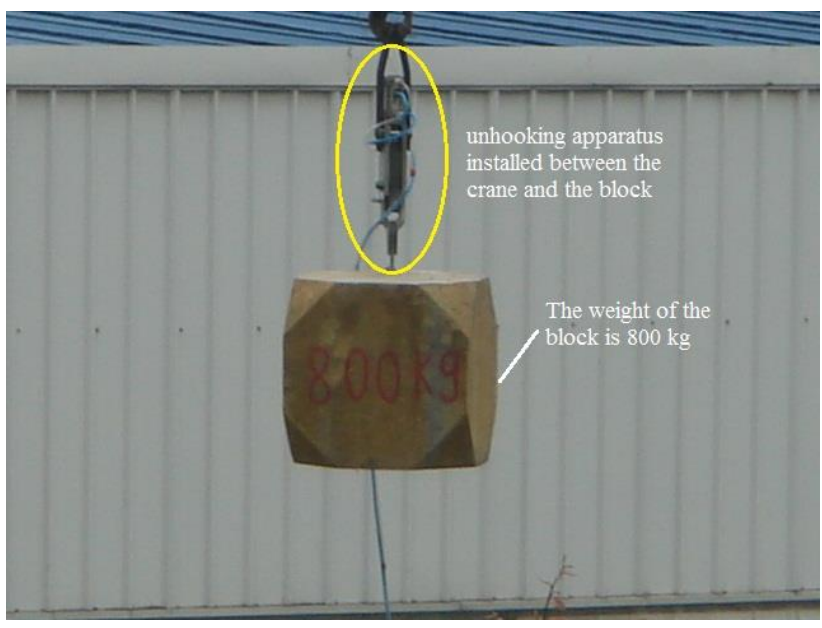

(b)

Fig. 5. (a) Cubic block of 14-face polyhedron; (b) an unhooking apparatus installed between the crane and the block.

the block can fall along with the plumb line and impact the mid-span of the system, as shown in Fig. 3b. This makes the response of the steel vaulted structure under impact symmetrical. Dynamical strain gauges are pasted on half of the steel vaulted structure and connected to a data acquisition station. The sample rate of the data acquisition station used for the test is $50 \mathrm{KHz}$. The pasted strain gauges are located at $\mathrm{T} 0$, $\mathrm{T} 1-1, \mathrm{~T} 1-2, \mathrm{~T} 1-3, \mathrm{~T} 1-4$ and $\mathrm{T} 1-5$, as shown in Fig. 3a. There are strain gauges along three directions at T0, T1-1, and $\mathrm{T} 1-2$, and one direction is along the hoop of the flexible rock-shed, the other is along the axis of the rock-shed and the last is at a $45^{\circ}$ angle of the axis of the rock-shed. There are strain gauges along two directions at $\mathrm{T} 1-3, \mathrm{~T} 1-4$, and $\mathrm{T} 1-5$, and one direction is along the hoop of the flexible rock-shed, the other is along the axis of the rock-shed. A high-speed camera (300 frames per second) is used to record the impact of the block onto the structure. Load cells are used for the measurement of tensile force acting on the cable anchors and the horizontal cables (Fig. 3a). Experimental data is stored for subsequent extraction. 
Table 2. The maximum deformation of flexible nets and load on the cable anchor and horizontal cable.

\begin{tabular}{lccc}
\hline Item & $\begin{array}{c}\text { Maximum deformation } \\
\text { of flexible nets }(\mathrm{m})\end{array}$ & $\begin{array}{c}\text { Load on the } \\
\text { cable anchor }(\mathrm{kN})\end{array}$ & $\begin{array}{c}\text { Load on the } \\
\text { horizontal cable }(\mathrm{kN})\end{array}$ \\
\hline Results & 2.310 & 21.4 & 29.5 \\
\hline
\end{tabular}
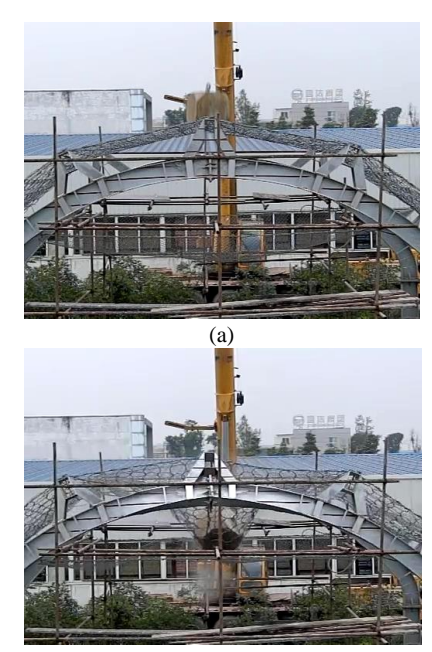

(c)

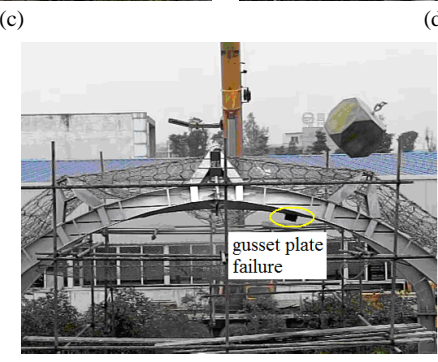

(e)

Fig. 6. Key point frames of video camera. (a) Block contacting with rock-shed (the 15th frame); (b) block down to the lowest point and steel vaulted structure beginning to rebound (the 58th frame); (c) block still rebounding and steel vaulted structure stopping rebounding (the 83th frame); (d) block rebounding off flexible rock-shed (the 175th frame); (e) block flying off one side of rock-shed (the 500th frame).

\section{Experimental results and discussions}

From the high-speed camera recorded frames, the time lapse $T$ between the first contact of the block with the flexible rock-shed and a concerned time can be evaluated by

$T=\frac{f_{2}-f_{1}}{f}$,

where $f_{1}$ is the number of frames at the first contact of the block with the rock-shed; $f_{2}$ is the number of frames corresponding to the concerned time; $f$ is the recording frequency.

Key point frames of video camera as recorded during the impact phase are selected (Fig. 6), including that of the block contacting with the rock-shed (the 15th frame); the block at the lowest point and the steel vaulted structure beginning to rebound (the 58th frame); the block still rebounding and the steel vaulted structure stopping the rebounding (the 83th frame); the block rebounding off the flexible rock-shed (the 175 th frame); and the block flying off one side of the rockshed (the 500th frame). The respective time lapses can be calculated from Eq. (3) and are listed in Table 1. In addition, the maximum deformation of the flexible nets is also clearly visible in Fig. 6 and the maximum loads acting on the cable anchor and horizontal cable are recorded by the load cells and are listed in Table 2.

As can be seen in Fig. 6, the flexible rock-shed successfully withstands the impact of the block with a kinetic energy of about $250 \mathrm{~kJ}$ and no rupture of the flexible nets and cables is observed. In the impact process, when the block rebounds, the steel vaulted structure rebounds simultaneously, but part of the residual deformation is preserved. At this moment, some components of the rock-shed absorb a large portion of impact energy through the elastic-plastic deformation. The steel vaulted structure undergoes plastic distortion but can continue to be used after some maintenance. As shown in Table 1 , the impact time period is $0.143 \mathrm{~s}$, followed by a rebounding period up to $1.617 \mathrm{~s}$. As can be seen in Table 2, the maximum deformation of the flexible nets is $2.31 \mathrm{~m}$, resulting in a safety distance of $4.690 \mathrm{~m}$ which is greater than traffic vehicle height (maximum $4.0 \mathrm{~m}$ ). The loads on the cable anchor and horizontal cable are $21.4 \mathrm{kN}$ and $29.5 \mathrm{kN}$, respectively. So the construction of the cable anchor used in the structure is easier and the diameter of the horizontal cable can be reduced compared to the current design with diameter $18 \mathrm{~mm}$ (the tensile load is greater than $190 \mathrm{kN}$ ) or even can be canceled.

Figure 7 shows the strain history at various locations as recorded by the strain gauges. It represents a typical timehistory of strains throughout a free fall impact test, and in Fig. 7a, strains on the steel vaulted structure at each pasting location first rapidly increase and reach the peak in a time interval of about $0.14 \mathrm{~s}$, then the block and steel vaulted structure rebound until the structure stops rebounding and strains decrease and reach the stability in a time interval of about $0.25 \mathrm{~s}$. The results coincide well with data obtained by the high-speed camera. At the pasting locations T0, T1-1 and T1-2, residual strains are observed after stabling, indicating permanent plastic deformation renders within the range of the pasting locations. However, at the pasting locations T13, T1-4 and T1-5, the strains stabilizes at approximately 0 . 


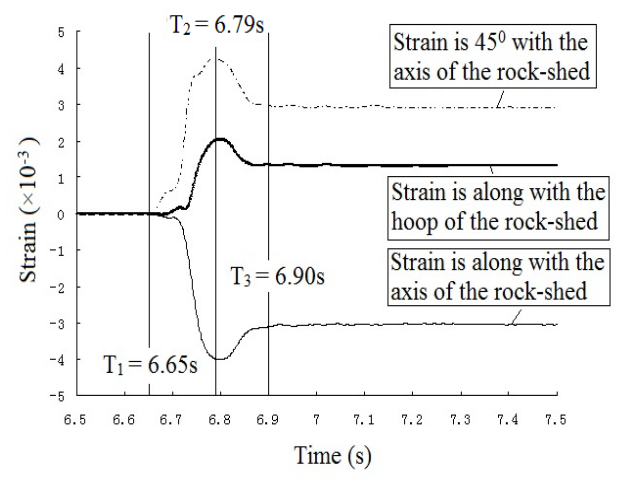

(a)

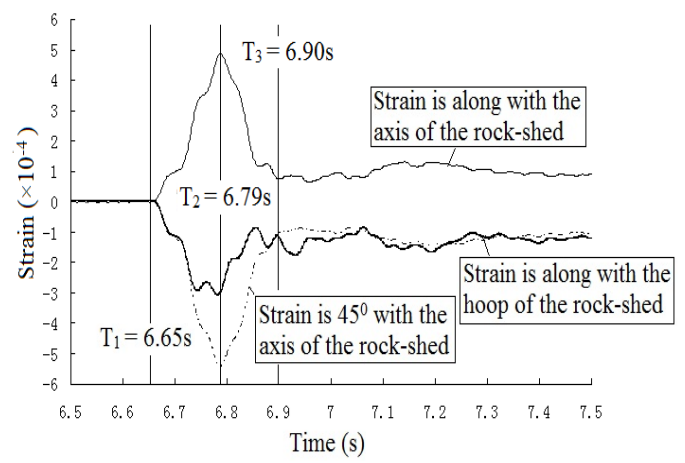

(c)

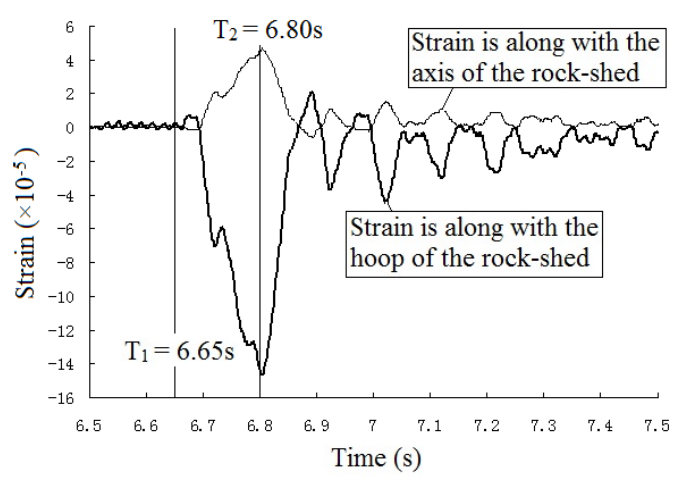

(e)

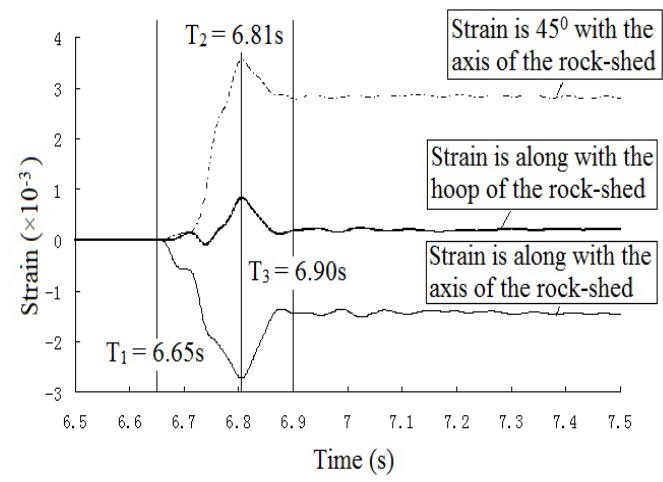

(b)

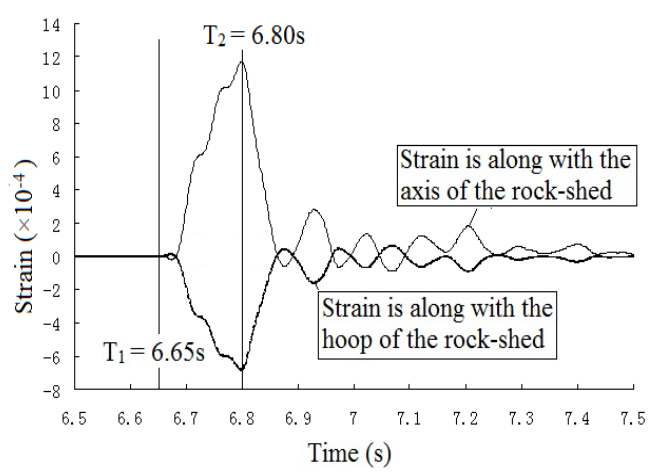

(d)

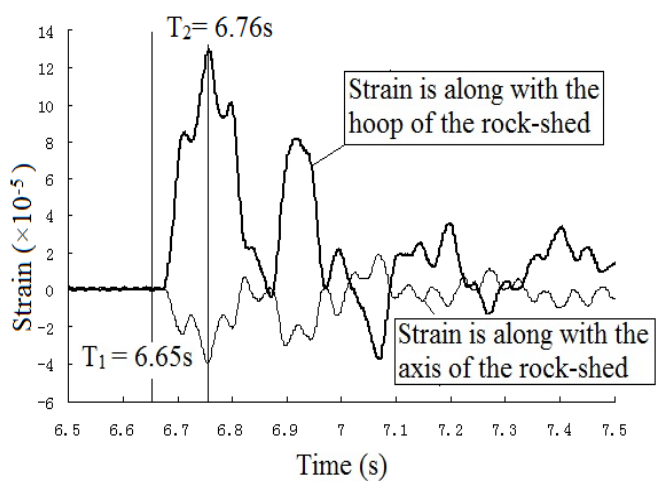

(f)

Fig. 7. The time-strain diagrams as recorded by the strain gauges. (a) Time-strain diagram at T0; (b) time-strain diagram at T1-1; (c) time-strain diagram at T1-2; (d) time-strain diagram at T1-3; (e) time-strain diagram at T1-4; (f) time-strain diagram at T1-5.

Therefore, at these three pasting locations, the deformation is nearly elastic, which indicates that the load on the column of the steel vaulted structure is small, and the cross-section size of the columns and shearing supports can be decreased compared to the current design. The design of the flexible rockshed does not need a massive foundation due to the flexibility of the structure and construction of such foundations is easier and cheaper than the reinforced concrete rock-shed. Figure 7 also shows that the peak values of strain at $\mathrm{T} 0$ and $\mathrm{T} 1-1$ and the values of residual strains after stabilizing are higher by nearly one order of magnitude than those at other measuring locations. Thus, more serious distortion of the steel vaulted structure occurs within the range of T0 and T1-1.

Under the impact of the block, longitudinal support cables and flexible nets together cause the inward inclination of the net-hanging bracket and the angle is about $35^{\circ}$, resulting in the distortion of the arched beams (Fig. 8a). The longitudinal supports at the two sides of mid-span support the 

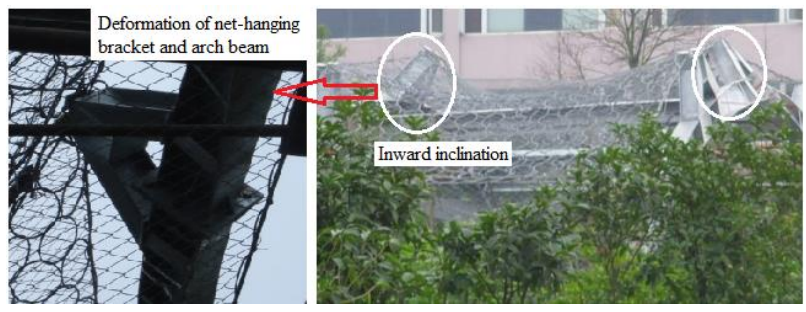

(a)

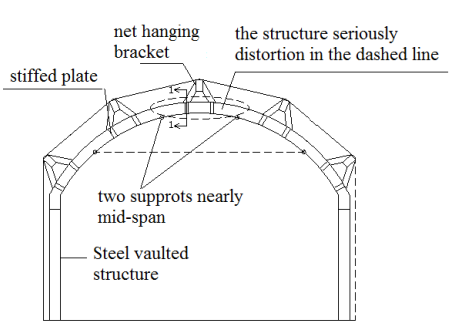

(b)

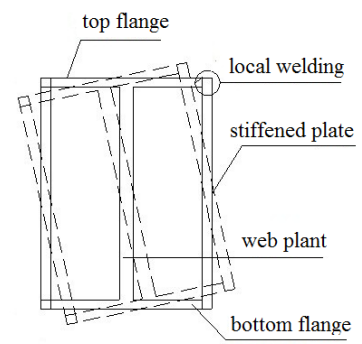

(c)
Fig. 8. The most serious distortion occurred between the two longitudinal supports nearly mid-span. (a) The picture of the distorted arched beam; (b) the schematic distortion drawing of the structure; (c) the detail cross-sectional deformation of arch beams.

arched beams, and therefore the most serious distortion occurs between the two longitudinal supports nearly mid-span (Fig. 8b).

An 1-1 cross section near the two longitudinal supports at mid-span is selected and the detail deformation is shown in Fig. 8c. The solid lines indicate the non-distorted cross section of arched beam, while the dashed lines indicate the distorted cross section of arched beam (without considering the distortion of the cross section of the arched beam). As can be seen in Fig. 8c, due to the effect of stiffened plates connected to the net-hanging bracket between the top and the bottom flanges of the arched beam, the top and the bottom flange plates rotated inside simultaneously. Stiffened plates on one side were subjected to compression force and on the other side were subjected to tensile force. Because the external load is greater than the restriction effect of the stiffened plates, the bending capacity differed between stiffened plates and the top and the bottom flanges of the arched beam, serious distortion occurred at the arched beam and the stiffened plates (Fig. 8a). As a result, the capability of stiffened plates to restrict general distortion was deduced, and the flanges and web plant of the arched beams were distorted. In order to increase the capacity of the stiffened plants to restrict the distortion of the structure, the width and the thickness of the stiffened plants should be increased.

The forces applied on the gusset plates welded to the top flanges, bottom flanges of the arched beam and the longitudinal supports are complicated, including shearing forces, bending moments and axial forces, the local welding is eas-

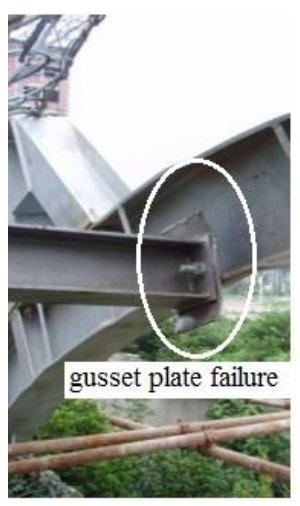

(a)

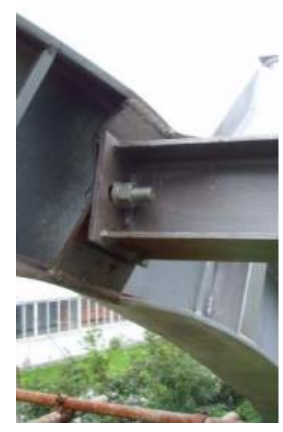

(b)

Fig. 9. (a) One of the gusset plates failure; (b) The detail deformation at the gusset plate.

ier to be broken off. As can be seen in Figs. 6d, e and 9a, one of the gusset plates failed and the local welding spot is broken off, while the other gusset plates buckled and the flanges deflected seriously (Fig. 9b). The longitudinal supports did not deform much because the welding locations between the gusset plates and the top and bottom flanges were too weak and could be easily damaged. Therefore, in order to restrict the distortion of the arch beams, the longitudinal supports should be directly connected to a web plate of the beam and the thickness at the connection location between longitudinal support and the web plate of the beam should be increased to prevent local damage.

Figure 10 shows the detail deformation of the components in the flexible rock-shed after the impact of the rock block. As can been seen in Fig. 10a, the ring nets and the wire meshes are all connected with the hoop cables by sewing cables. In the experiment, the sawing cables render no fracture or looseness. In addition, the cable clips are fixed and no sliding is observed. The flexible nets hang down about $0.6 \mathrm{~m}$ because of the residual deformation of the arch beams after impact of the block. The longitudinal support cable directly impacted by the block is highly deformed and the 


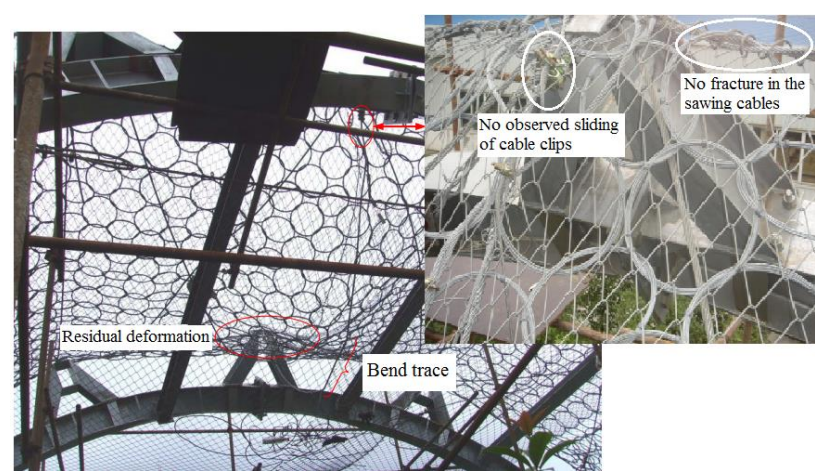

(a)

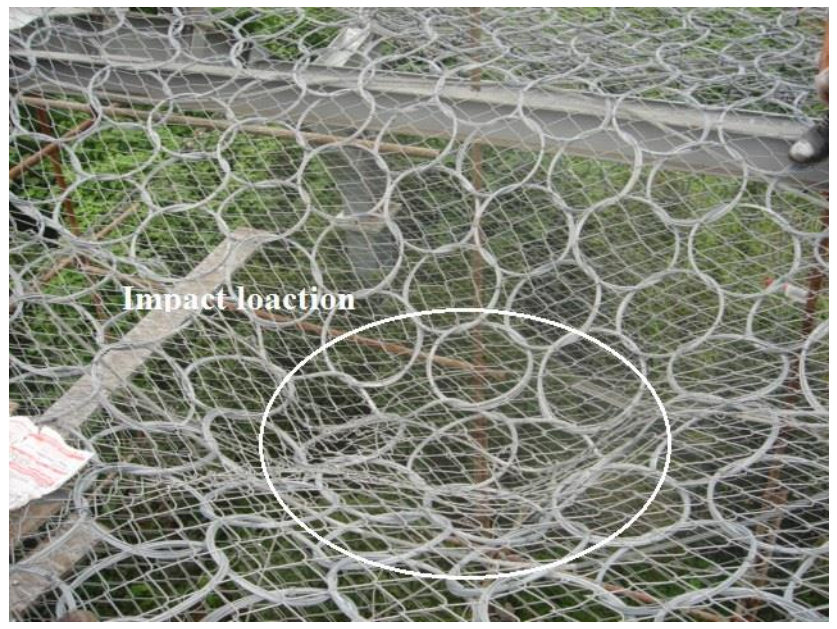

(b)

Fig. 10. The detail deformation of the components in the flexible rock-shed after the impact of the rock block.

impact location of the cable retained an approximately $0.6 \mathrm{~m}$ bending trace. As can be seen in Fig. 10b, single rings in the ring nets do not deform much, and the ring nets on the whole do not undergo significant deformation or damage.

\section{Conclusion and outlook}

A new concept of flexible rock-shed protection structure is proposed. The flexible rock-shed is mainly composed of a steel vaulted structure and flexible nets. Based on the ETAG 027 European guideline and testing procedures for concrete rock-sheds, the test procedure is designed and carried out to evaluate the functional performance on the flexible rockshed. Testing results show that the rock-shed performs well under an impact of a rock block with energy of $250 \mathrm{~kJ}$ and velocity of $25 \mathrm{~m} \mathrm{~s}^{-1}$. Due to the flexibility of the structure, the loads on the column, cable anchor and the horizontal cable are smaller and the section of the column and shearing support and the diameter of the horizontal cable can be reduced. In addition, in order to minimize the possibility of steel vaulted structure damage and to decrease the mainte- nance costs on the structure, the width and the thickness of the stiffened plants should be increased and the longitudinal supports should be directly connected to web plate of the beams and the thickness at connection location between longitudinal support and web plate of the beam should be increased to prevent local damage.

The flexible rock-shed mixes flexible barriers and structural rock-sheds, and the protection mode for this structure is different from the flexible barriers, but the same as the rock-sheds. Therefore, this solution possesses the advantages of both the flexible barriers and the concrete rock-sheds and overcomes some limits on them. It is cheaper than the concrete rock-shed with the same energy protection capacity. It is easier to be constructed and quickly installed, requiring little equipment. It is unnecessary to evaluate the possible paths of detachable rockfall, such as the bounding height and the runout distance, etc. It is suitable for construction on bridges because of its lightweight structure. It can be manufactured in a factory and field-assembled and is especially suitable for emergency construction and maintenance.

However, there are some limiting factors in the case of the flexible rock-shed according to the rockfall settings and the experimental investigation. The present flexible rock-shed can only be used for low (about $250 \mathrm{~kJ}$ energy) rockfall settings, considering economic factors, safety distance and technical limitations. If the structure has experienced a rockfall event with full energy protection capacity, the vaulted structure would be too deformed and require immediate maintenance. The flexible rock-shed cannot be used if the frequency and intensity of rockfall is higher or if the perpetual protection structures are needed from the engineering points and economic factors of view.

Although the procedure for testing the flexible rock-shed is designed with reference to testing procedures of flexible barriers and reinforced concrete rock-sheds, the flexible rockshed is different from the flexible barrier and concrete rockshed, and there are some limits of the present experimental investigation that deserve to be discussed in the future:

1. The failure or deformation models of this structure would be possible depending much on the type of impact (vertical impact or oblique impact), the location of impact (on the central location, on the eccentric location or on the edge), the impacted structural element (flexible nets, support cables or vaulted structure) and the mass, the volume and the shape of the block. In the present test, only one condition of structure impacted by the block on the middle-span location was tested. How the conditions above influence the performance of the structure needs to be further investigated.

2. In the experiment, the block rebounded after the collision and impacted the net-hanging bracket when the block flew off one side of the rock-shed. For safety, the flexible rock-shed should absorb much more energy 
via plastic deformation and friction and the rebounding energy of the block should be reduced.

3. The single-span flexible rock-shed is designed and tested in this paper, but a multi-span flexible rock-shed is much different from the single span structure because the other span structures can share the lateral binding force and this would improve the deformation of the vaulted structure.

4. Although the full-scale test provides useful information for design purposes of the structure, the loading mechanisms and energy dissipation by the flexible nets, the support cables and the vaulted structure are not clear, and these would be conducted by the numerical methods for design or optimization purposes or for parametric analyses for the flexible rock-shed.

Acknowledgements. The present research is funded by the National Science and Technology Support Program of China (2012BAK05B02), the National Natural Science Foundation of China (Grant No. 51378495) and the Natural Science Foundation Project of CQ CSTC (2012jjB30004).

Edited by: B. D. Malamud

Reviewed by: two anonymous referees

\section{References}

Agliardi, F., Crosta, G. B., and Frattini, P.: Integrating rockfall risk assessment and countermeasure design by 3-D modelling techniques, Nat. Hazards Earth Syst. Sci., 9, 1059-1073, 2009, http://www.nat-hazards-earth-syst-sci.net/9/1059/2009/.

Azzoni, A. and de Freitas, M. H.: Experimental gained parameters, decisive for rock fall analysis, Rock Mech. Rock Eng., 28, 111124, 1995.

Blanco-Fernandez, E., Castro-Fresno, D., del Coz Diaz, J., and López, L.: Flexible systems anchored to the ground for slope stabilisation?: Critical review of existing design methods, Eng. Geol., 122, 129-145, 2011.

Bertolo, P., Oggeri, C., and Peila, D.: Full-scale testing of draped nets for rock fall protection, Can. Geotech. J., 46, 306-317, 2009.

Bhatti, A. Q. and Kishi, N.: Impact response of RC rock-shed girder with sand cushion under falling load, Nucl. Eng. Des., 240, 2626-2632, 2010.

Buzzi, O., Spadari, M., Giacomini, A., Fityus, S., and Sloan, S. W.: Experimental testing of rockfall barriers designed for the low range of impact energy, Rock Mech. Rock Eng., 46, 701-712, 2013.

Castro-Fresno, D., del Coz Diaz, J., López, L., and Nieto, P. G.: Evaluation of the resistant capacity of cable nets using the finite element method and experimental validation, Eng. Geol., 100, 1-10, 2008.

Cazzani, A., Mongiovi, L., and Frenez, T.: Dynamic finite element analysis of interceptive devices for falling rocks, Int. J. Rock Mech. Min. Sci., 39, 303-321, 2002.
Chau, K. T, Wong, R. H., and Wu, J.J.,: Coefficient of restitution and rotational motions of rockfall impacts, Int. J. Rock Mech. Min., 39, 69-77, 2002.

Crosta, G. B. and Agliardi, F.: Parametric evaluation of 3-D dispersion of rockfall trajectories, Nat. Hazards Earth Syst. Sci., 4, 583-598, doi:10.5194/nhess-4-583-2004, 2004.

Delhomme, F., Mommessin, M., Mougin, J.P., and Perrotin, P.: Behavior of a structurally dissipating rock-shed: experimental analysis and study of punching effects, Int. J. Solids Struct., 42, 4204-4219, 2005.

Delhomme, F., Mommessin, M., Mougin, J.P., and Perrotin, P.: Simulation of a block impacting a reinforced concrete slab with a finite element model and a mass-spring system, Eng. Struct., 29, 2844-2852, 2007.

Dhakal, S., Bhandary, N. P., Yatabe, R., and Kinoshita, N.: Experimental, numerical and analytical modelling of a newly developed rockfall protective cable-net structure, Nat. Hazards Earth Syst. Sci.,11, 3197-3212, 2011.

Dhakal, S., Bhandary, N. P., Yatabe, R., and Kinoshita, N.: Numerical and analytical investigation towards performance enhancement of a newly developed rockfall protective cable-net structure, Nat. Hazards Earth Syst. Sci., 12, 1135-1149, 2012, http://www.nat-hazards-earth-syst-sci.net/12/1135/2012/.

EOTA: ETAG 027 - guideline for European technical approval of falling rock protection kits, Tech. rep., European Organization for Technical Approvals, Brussels, 2008.

Gentilini, C., Gottardi, G., Govoni, L., Mentani, A., and Ubertini, F.: Design of falling rock protection barriers using numerical models, Eng. Struct., 50, 96-106, 2013

Gerber, W.: Guideline for the approval of rockfall protection kits. Swiss Agency for the Environment, Forests and Landscape (SAEFL) and the Swiss Federal Research Institute WSL, Berne, 2001.

Giacomini, A., Thoeni, K., Lambert, C., Booth, S., and Sloan, S. W.: Experimental study on rockfall drapery systems for open pit highwalls, Int. J. Rock Mech. Min. Sci., 56, 171-181, 2012.

Giani, G., Giacomini, A., Migliazza, M., and Segalini, A.: Experimental and theoretical studies to improve rock fall analysis and protection work design, Rock Mech. Rock Eng., 37, 369-389, 2004.

Guzzetti, F., Crosta, G., Detti, R., and Agliardi, F.,: Stone: a computer program for the three-dimensional simulation of rock-falls, Comput. Geosci., 28, 1079-1093, 2002.

Gottardi, G. and Govoni, L.: Full-scale modelling of falling rock protection barriers, Rock Mech. Rock Eng., 43, 261-274, 2010.

Kawahara, S. and Muro. T.: Effects of dry density and thickness of sandy soil on impact response due to rockfall, J. Terramechanics, 43, 329-340, 2006.

Kishi, N., Konno, H., Ikeda, K., and Matsuoka, K.: Prototype impact tests on ultimate impact resistance of PC rock-sheds, Int. J. Impact. Eng., 27, 969-985, 2002.

Labiouse, V., Descoeudres, F., and Montani, S.: Experiment study of rock sheds impacted by rock blocks, Struct. Eng. Int., 6, 171176, 1996.

Lambert, S., Bourrier, F., and Toe, D.: Improving three-dimensional rockfall trajectory simulation codes for assessing the efficiency of protective embankments, Int. J. Rock Mech. Min. Sci., 60, 26-36, 2013. 
Masuya, H., Amanuma, K., Nishikawa, Y., and Tsuji, T.: Basic rockfall simulation with consideration of vegetation and application to protection measure, Nat. Hazards Earth Syst. Sci., 9, 1835-1843, doi:10.5194/nhess-9-1835-2009, 2009.

Mougin, J. P., Perrotin, P., Mommessin, M., Tonnelo, J., and Agbossou, A.: Rock fall impact on reinforced concrete slab: an experimental approach, Int. J. Impact. Eng., 31, 169-183, 2005.

Muraishi, H., Samizo, M., and Sugiyama, T.: Development of a flexible low energy rockfall protection fence, Q. Rep. Rtri., 46, 161166, 2005.

Nicot, F., Cambou, B., and Mazzoleni, G.: Design of rockfall restraining nets from a discrete element modelling, Rock Mech. Rock. Eng., 34, 99-118, 2001.

Pantelidis, L. and Kokkalis, A.: Designing passive rockfall measures based on computer simulation and field experience to enhance highway safety, Int. J. Rock Mech. Min. Sci., 48, 13691375, 2011.

Peila, D. and Ronco, C.: Technical note: Design of rockfall net fences and the new ETAG027 European guideline, Nat. Hazards Earth Syst. Sci., 9, 1291-1298, 2009, http://www.nat-hazards-earth-syst-sci.net/9/1291/2009/.

Peila, D., Pelizza, S., and Sassudelli, F.: Evaluation of behaviour of rockfall restraining nets by full scale tests, Rock Mech. Rock Eng., 31, 1-24, 1998.

Pichler, B., Hellmich, C., and Mang, H.: Impact of rocks onto gravel design and evaluation of experiments, Int. J. Impact. Eng., 31, 559-578, 2005.

Sasiharan, N., Muhunthan, B., Badger, T., Shu, S., and Carradine, D.: Numerical analysis of the performance of wire mesh and cable net rockfall protection systems, Eng. Geol., 88, 121-132, 2006.
Schellenberg, K.: On the design of rockfall protection galleries An analytical approach for a performance based design, SVH, 196 pp., 2009

Smith, D. D. and Duffy, J. D.: Field tests and evaluation of rockfall restraining nets. CA/TL-90/05, Final Report, California Department of Transportation, Office of Transportation, Materials and Research, Sacramento, CA, USA, 1990.

Spadari, M., Giacomini, A., Buzzi, O., and Hambleton, J.: Prediction of the bullet effect for rockfall barriers: a scaling approach, Rock Mech. Rock Eng., 45, 131-144, 2012

Topal, T., Akin, M., and Ozden, U.: Assessment of rockfall hazard around Afyon Castle, Turkey, Environ. Geol., 53, 191-200, 2007.

Vogel, T., Labiouse, V., and Masuya, H.: Rockfall protection as an integral task, Struct. Eng. Int., 19, 304-312, 2009.

Volkwein, A.: Numerical simulation of flexible rockfall protection systems. Proc. of The ASCE International Conference on Computing in Civil Engineering, Cancun, Mexico, 1-11, doi:10.1061/40794(179)122, 2005.

Volkwein, A., Schellenberg, K., Labiouse, V., Agliardi, F., Berger, F., Bourrier, F., Dorren, L., Gerber, W., and Jaboyedoff, M.: Rockfall characterization and structural protection - A review, Nat. Hazards Earth Syst. Sci., 11, 2617-2651, 2011, http://www.nat-hazards-earth-syst-sci.net/11/2617/2011/.

Wendeler, C., Volkwein, A., and Biedermann, B.: Eine ?exible Steinschlag galerie im Hochenergiebereich als Varante zu einer Betongalerie oder Tunnellösung Bemessung und Anwendungsbeispiel, Zeitschrift für Wildbach-, Lawinen-, Erosions- und Steinschlagschutz77, 171, 90-97, 2013 (in German). 